\title{
Fabrication of fairly efficient solid state dye-sensitized solar cells with a dense blocking layer
}

\author{
Sho IGARASHI, ${ }^{\dagger}$ Hitoshi SAKAMOTO, Kazuma NIUME, Yuji TANAKA, \\ Ryo TAMAKI, Shohei ODU and Masayuki NAGAI \\ Department of Energy Science and Nuclear Engineering, Energy Materials Chemistry Laboratory, \\ Advanced Research Laboratory, Tokyo City University, 8-15-1 Todoroki, Setagaya-ku, Tokyo 158-0082, Japan
}

\begin{abstract}
This paper is concerned with the synthesis, characterization, and electrochemical properties of all solid state dye-sensitized solar cells (SSDSSCs) with a dense $\mathrm{TiO}_{2}$ layer. The dense $\mathrm{TiO}_{2}$ layer, which was prepared from titanium hydroxide and titanium tetra isopropoxide precursor, has been characterized by $\mathrm{X}$-ray diffraction, scanning electron microscopy. The experimental results showed that the $\mathrm{TiO}_{2}$ layer formed using titanium hydroxide precursor with a thickness of about $100 \mathrm{~nm}$ was composed of crack free anatase-phase. The dense $\mathrm{TiO}_{2}$ layer is found to improve the short circuit current density $(J \mathbf{s c})$, leading to enhancement in the conversion efficiency $(\eta)$ of the SSDSSCs from 2.92 to $3.60 \%$.
\end{abstract}

๑2013 The Ceramic Society of Japan. All rights reserved.

Key-words : Solid state dye-sensitized solar cells, Blocking layer, Interface, Titanium dioxide, PEDOT, Cul

[Received December 25, 2012; Accepted March 4, 2013]

\section{Introduction}

Recently dye-sensitized solar cells (DSSCs) have been intensively studied because of their low cost and high efficiency comparable to amorphous silicon solar cells. ${ }^{1)-3)}$ However, normal DSSCs using liquid electrolytes have several technological problems such as dye desorption, solvent evaporation, leakage and so on. Much effort for solving them has been made to replace the liquid electrolyte with quasi-solid or solid materials, ${ }^{4)-6)}$ organic hole conductors, ${ }^{7)-13)}$ and inorganic hole conductors. ${ }^{14)-25)}$ Among these materials, CuI and $\mathrm{CuSCN}$ are suitable as hole conductors in SSDSSCs because these materials have high optical transmittance, high electrical conductivity and suitable valence band energy level which allows hole injection from excited ruthenium dye molecules. However, SSDSSCs exhibit largely low conversion efficiency in comparison with normal DSSCs using liquid electrolyte. The reasons are as follows; solid hole conductors penetrates porous $\mathrm{TiO}_{2}$ layer resulting in direct contact with the transparent conductive glass electrode, and it may cause short-circuit. Therefore, it is necessary to form a dense blocking layer between porous $\mathrm{TiO}_{2}$ layer and transparent conductive glass electrode to prevent them from direct contact. It is well known that compactness of the blocking layer dominates performance of SSDSSCs. ${ }^{26)}$ However, a precursor of the titanium alkoxide which has been usually used for the formation of blocking layer is useless to prepare dense blocking layers, since cleavage due to decomposition and evaporation of bulky alkoxy groups during heat-treatment may be left in the layer. ${ }^{26)}$

In this paper, we propose better method for preparation of the dense $\mathrm{TiO}_{2}$ blocking layer on FTO through an alkoxy group free precursor. By the use of the present method, it is found that $\mathrm{CuI}$ based SSDSSCs with the dense $\mathrm{TiO}_{2}$ blocking layer shows enhancement in the conversion efficiency $(\eta)$ mainly due to the improvement of the short-circuit current (Jsc).

Corresponding author: S. Igarashi; E-mail: g1191901@tcu.ac.jp

\section{Experimental}

\subsection{Preparation of $\mathrm{TiO}_{2}$ blocking layer}

Titanium tetra-isopropoxide $(0.47 \mathrm{~g})$, ethanol $(3.95 \mathrm{~g})$, and hydrochloric acid $(30 \%, 0.13 \mathrm{~g})$ was mixed together and stirred for $1 \mathrm{~h}$ (solution A).

Titanium (IV) chloride solution $(16.5 \%, 2.32 \mathrm{~g})$ and water $(13.5 \mathrm{~g})$ were mixed and stirred for $1 \mathrm{~h}$. Subsequently, ammonia solution was added to the resultant solution so as to adjust the $\mathrm{pH}$ at 8 , leading to the formation of precipitates. The precipitates were separated through filtration, washed, and collected. Tetramethyl ammonium hydroxide solution $(15 \%, 3.0 \mathrm{~g})$ was added to the precipitates. The mixture was stirred for $24 \mathrm{~h}$ at $60^{\circ} \mathrm{C}$, in order to form a transparent clear solution (solution B).

Blocking layers were prepared by spin-coating of the solutions A and B on a FTO glass substrate (Asahi glass). Subsequently, in order to prepare transparent titanium oxide films, each substrate was dried at $100^{\circ} \mathrm{C}$ for $10 \mathrm{~min}$ in air, and heated at $500^{\circ} \mathrm{C}$ for $30 \mathrm{~min}$ in air.

\subsection{Fabrication of SSDSSC}

Porous $\mathrm{TiO}_{2}$ films were prepared by coating the $\mathrm{TiO}_{2}$ paste ${ }^{27)}$ onto the blocking layer/FTO glass substrate using the squeeze printing technique, subsequently, the electrodes were heated at $500^{\circ} \mathrm{C}$ for $30 \mathrm{~min}$ in air. The thickness of porous $\mathrm{TiO}_{2}$ film was about $7 \mu \mathrm{m}$. The electrode was immersed in $0.5 \mathrm{mM}$ ethanol solution of $\mathrm{N} 3$ dye for $24 \mathrm{~h}$ at room temperature. The CuIacetonitrile solution $(0.15 \mathrm{M})$ was lightly coated over the dyed electrode. After coating, the electrode was heated up to $80^{\circ} \mathrm{C}$ to evaporate the solvent. This process was repeated several times. The amount of $\mathrm{CuI}$ solution was about $0.06 \mathrm{ml} / \mathrm{cm}^{2}$. The counter electrode was prepared by coating the solution of polyethylene glycol(PEG) containing NCS group onto the ITO modified by poly(3,4-ethylene-dioxy-thiophene):poly(styrene-sulfonate) (PEDOT-PSS). The PEDOT modified ITO was prepared by spin-coating of PEDOT:PSS aqueous dispersion (Clevios $\mathrm{PH}$ ) on ITO and dried at $130^{\circ} \mathrm{C}$ for $30 \mathrm{~min}$ in air. The PEG contain- 
ing NCS groups was prepared by dissolving PEG20000 and guanidium thiocyanate $(1: 1)$ in acetonitrile and heated up to $130^{\circ} \mathrm{C}$ to evaporate the solvent. The $\mathrm{CuI} /$ dye/porous- $\mathrm{TiO}_{2} /$ blocking layer/FTO electrode was fixed together with the counter electrode. The resulting cells had an active area of $0.24 \mathrm{~cm}^{2}$.

\subsection{Characterization}

The local structure of the samples were examined by the use of fourier transformation infra-red spectrometer (FT-IR) (Perkin Elmer, SPECTRUM GX 2000R). The photo-electrochemical properties of the SSDSSCs were measured by recording the current-voltage (I-V) characteristics under illumination of AM 1.5 (1 Sun; $100 \mathrm{~mW} / \mathrm{cm}^{2}$ ) using a solar simulator (Yamashita Denso, YSS-80). The electrochemical impedance spectroscopy (EIS) of the SSDSSCs was conducted using a potentiostat (Solartron analytical, model 1287) equipped with an impedance analyzer (Solartron analytical, model 1260) under illumination of AM 1.5 using the solar simulator. The EIS measured in the frequency range of $0.1-10^{6} \mathrm{~Hz}$ and the $\mathrm{AC}$ amplitude was $50 \mathrm{mV}$ and set at open circuit voltage. The phase of $\mathrm{TiO}_{2}$ blocking layer was identified by X-ray diffraction (XRD) with monochromatic $\mathrm{Cu} \mathrm{K} \alpha$ radiation at $30 \mathrm{kV}, 20 \mathrm{~mA}$ (Philips, PW1790). The thickness and morphology of the blocking layers were examined by the use of a field-emission scanning electron microscope (Hitachi, S-4100). Thermo-gravimetric analysis (TG) and differential thermal analysis (DTA) were conducted using a TG/DTA thermal analyzer (Seiko Instruments TG/DTA300, $10^{\circ} \mathrm{C} / \mathrm{min}$ ) to characterize the solution $\mathrm{A}$ and $\mathrm{B}$ after dried at $70^{\circ} \mathrm{C}$.

\section{Result and discussion}

\subsection{FT-IR characterization}

Figure 1 shows the FT-IR spectrum of the samples from solution B and titanium hydroxide after they were dried at $40^{\circ} \mathrm{C}$. The broad peak at $3100-3600 \mathrm{~cm}^{-1}$ is assigned to the fundamental stretching vibration of free or bonded hydroxyl groups. This broad peak is presumed to be caused by the bending vibration of $\mathrm{H}_{2} \mathrm{O}$ as well as Ti-OH. Comparing the peak intensity with each other, the broad peak for the sample from solution $\mathrm{B}$ after dried at $40^{\circ} \mathrm{C}$ is weakened, indicating that the hydroxyl groups reduced for the sample from solution B.

\subsection{Analysis of the dense $\mathrm{TiO}_{2}$ layer}

Figure 2 shows the typical XRD patterns of the FTO and dense $\mathrm{TiO}_{2}$ layer-deposited FTO glasses. In Fig. 2(a), the diffraction peaks can be identified as a tetragonal rutile phase $\mathrm{SnO}_{2}$. In Fig. 2(b), a newly appeared peaks corresponding to the (101) of anatase-phase $\mathrm{TiO}_{2}$ are observed.

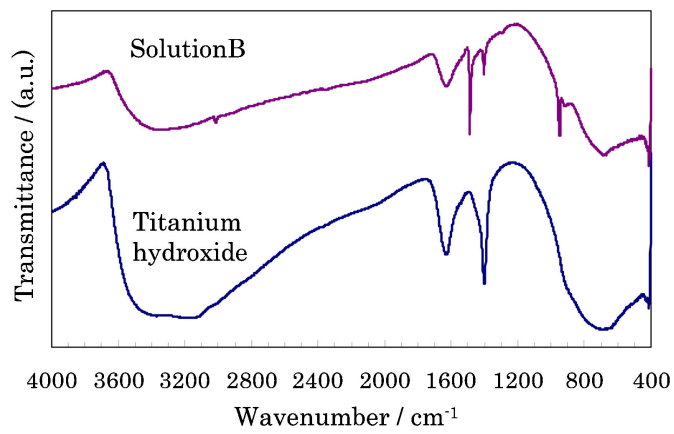

Fig. 1. FT-IR spectrum of the solution $\mathrm{B}$ and titanium hydroxide after dried at $40^{\circ} \mathrm{C}$ in vacuum.
Figure 3 shows the SEM images of the bare FTO glass and blocking $\mathrm{TiO}_{2}$ layer-deposited FTO glasses. From the surface SEM images, the surface of the bare FTO glass clearly exhibits the surface morphology of $\mathrm{SnO}_{2}$. The blocking $\mathrm{TiO}_{2}$ layerdeposited FTO glasses prepared from solution A have cracks. In contrast, a thin dense $\mathrm{TiO}_{2}$ layer (c.a. $100 \mathrm{~nm}$ ) formed from solution $\mathrm{B}$ has no cracks. Therefore, we can presume that it would prevent the conductive glass active electrode from contacting with the $\mathrm{CuI}$ electrolyte.

Figure 4 shows the TG/DTA curves of the samples from solutions $\mathrm{A}$ and $\mathrm{B}$ dried at $70^{\circ} \mathrm{C}$. In the TG curves, the total weight loss of those from solutions $\mathrm{A}$ and $\mathrm{B}$ in the temperature region up to $500^{\circ} \mathrm{C}$ are about 50 and $40 \%$, respectively. Additionally, since the sample from solution B was pyrolyzed at lower temperature under $250^{\circ} \mathrm{C}$, it may give rise to less thermal

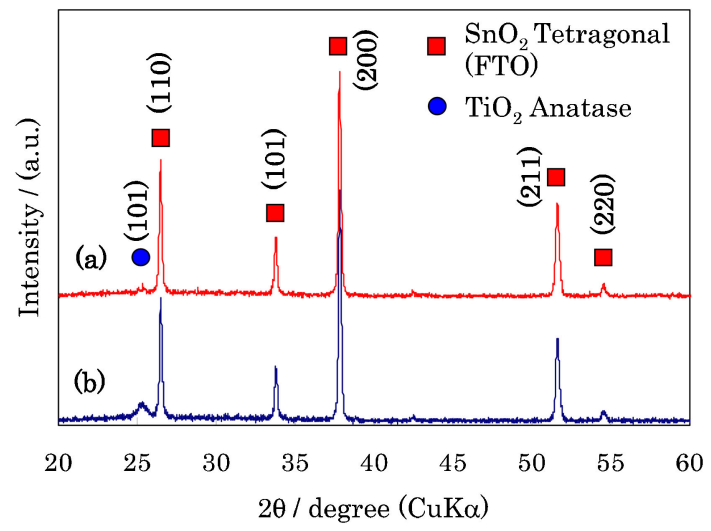

Fig. 2. XRD patterns of (a) the bare FTO and (b) the FTO covered with dense $\mathrm{TiO}_{2}$ blocking layer, FTO (square) and $\mathrm{TiO}_{2}$ (circle).
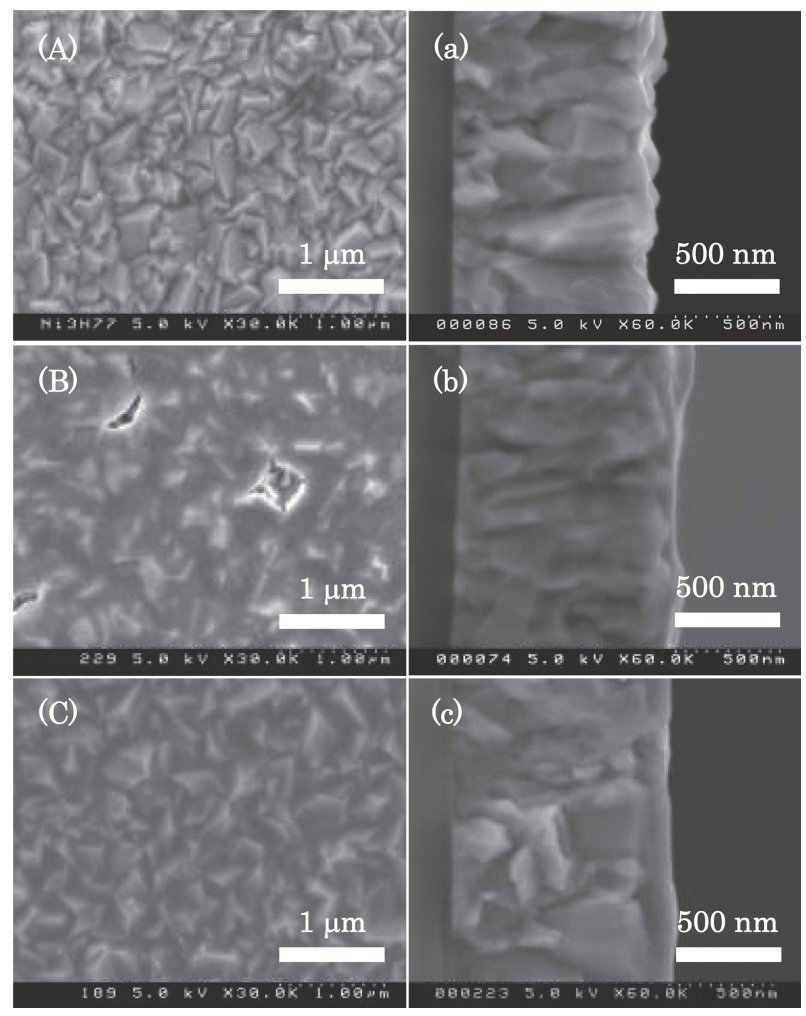

Fig. 3. Surface (A-C) and cross-section (a-c) SEM images for the bare FTO, blocking layer-deposited FTO substrates from the solutions $\mathrm{A}$ and $\mathrm{B}$. 

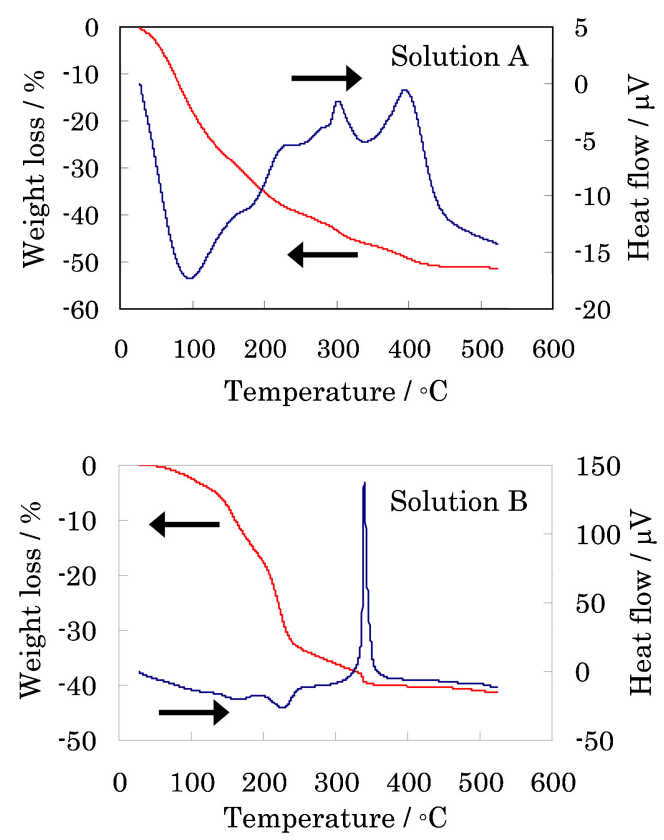

Fig. 4. TG/DTA curves of the solution $\mathrm{A}$ and $\mathrm{B}$ after dried at $70^{\circ} \mathrm{C}$.

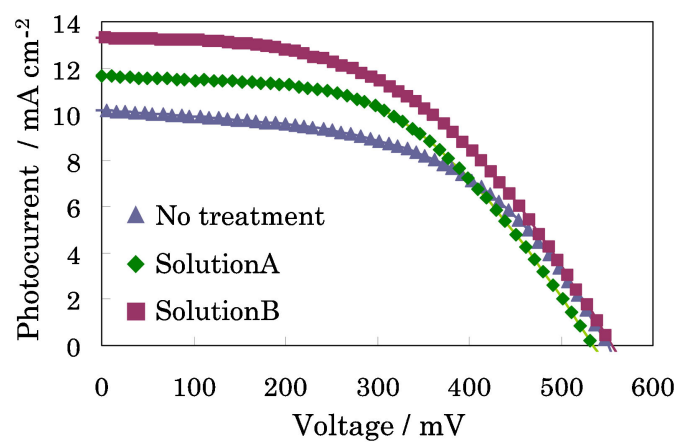

Fig. 5. Photocurrent-voltage characteristics of SSDSSCs.

Table 1. Photocurrent-voltage characteristics values of SSDSSCs

\begin{tabular}{lcccc}
\hline & Voc $(\mathrm{mV})$ & $J_{\text {sc }}\left(\mathrm{mA} / \mathrm{cm}^{2}\right)$ & $F . F$. & $\eta(\%)$ \\
\hline No treatment & 547 & 10.2 & 0.525 & 2.92 \\
Solution A & 532 & 11.7 & 0.512 & 3.17 \\
Solution B & 549 & 13.3 & 0.494 & 3.60 \\
\hline
\end{tabular}

contraction. Therefore, it is speculated that the crack-free dense $\mathrm{TiO}_{2}$ layer was formed from solution B probably due to the small total weight loss during heating and less thermal contraction.

\subsection{Photovoltaic performance}

The I-V curves of the DSSCs with and without the blocking layer are shown in Fig. 5 and the photovoltaic characteristics of these DSSCs were summarized in Table 1. Comparing with the DSSCs without the blocking layer, the performance of the SSDSSCs with the dense blocking layer, in terms of solar energy conversion efficienc $(\eta)$ and short-circuit current density $(J \mathrm{sc})$, was improved by $23.3 \%$ and $30.4 \%$, respectively. One of the main factors improving the $J_{\mathrm{Sc}}$ of the SSDSSCs may be the charge recombination at the $\mathrm{FTO}$ and $\mathrm{CuI}$ interfaces. It is reported in a previous study ${ }^{28)}$ that the $J_{\mathrm{sc}}$ is associated with the charge recombination at photocathode electrodes. Figure 6 is the com-

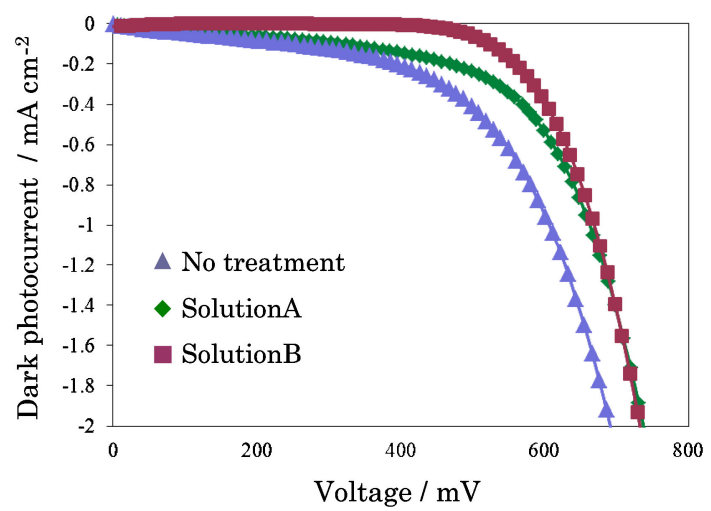

Fig. 6. Dark photocurrent-voltage characteristics of SSDSSCs.

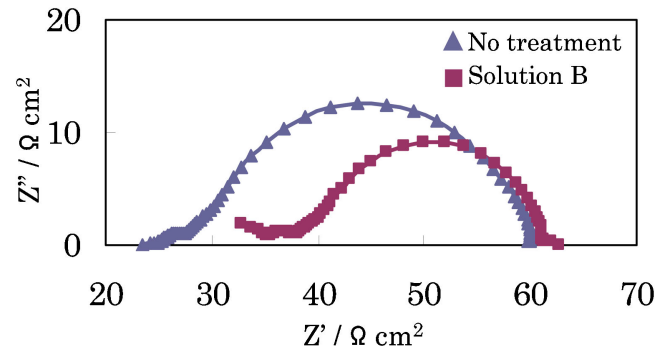

Fig. 7. Nyquist diagrams of impedance spectra obtained under illumination for the cells with no treatment (triangle) and the cell with blocking layer treated with solution B (square).

parison of the dark photocurrent characteristics of DSSCs with and without blocking layer. The onset of the dark current shifted to higher forward bias for the DSSCs with blocking layer. The increase of the onset potential and the reduction of the dark current demonstrated that the blocking layer successfully reduced the recombination. With the application of the dense blocking layer, the number of the recombination sites (bare FTO surface) are reduced, leading to reduction of the charge recombination in the SSDSSCs.

\subsection{Electrochemical impedance spectroscopy}

Figure 7 shows the electrochemical impedance spectra measured in the frequency range of $0.1-10^{6} \mathrm{~Hz}$ for the cell with no treatment and that treated with solution $\mathrm{B}$ at open circuit conditions. According to our previous study, ${ }^{29)}$ the counter electrode containing NCS groups as well as the NCS groups of the dye molecules were thought to interact with CuI. The specific interaction of $\mathrm{CuI}$ with the NCS groups of both electrodes could promote the injection of the hole into the electrodes. Based on our previous studies, ${ }^{29), 30)}$ the equivalent circuit of these cells composed of three $R C$ parallel circuit is shown in Fig. 8. $R_{1} C_{1}$, $R_{2} C_{2}$, and $R_{3} C_{3}$ corresponding to charge transfer resistances and electrochemical capacitances are thought to be due to the dye on $\mathrm{TiO}_{2} / \mathrm{CuI}, \mathrm{CuI} /$ guanidium thiocyanate, guanidium thiocyanate/ PEDOT:PSS interface, respectively. $R_{0}$ indicates the series internal resistance of SSDSSCs such as the resistance of transparent conducting glasses. These values of $R, C$, and $\alpha$ [phase of Constant Phase Elements: $\left.Z_{\mathrm{CPE}}=1 / \mathrm{T}(\mathrm{j} \omega)^{\alpha}\right]$ were calculated by fitting the components of the equivalent circuit with Z-view software and are exhibited in Table 2. $R_{1}$ corresponding to the resistance of $\mathrm{TiO}_{2}$.dye/CuI for the cell with no treatment showed almost the same value as that of the cell treated with solution B. 


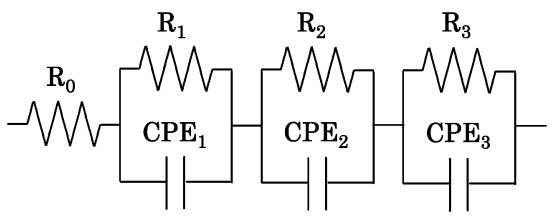

Fig. 8. The equivalent circuit of SSDSSCs.

Table 2. The R, C parameters calculated by fitting the impedance spectra of SSDSSCs

\begin{tabular}{lcc}
\hline & No treatment & Solution B \\
\hline$R_{0}\left(\Omega \mathrm{cm}^{2}\right)$ & 24.4 & 31.3 \\
$R_{1}\left(\Omega \mathrm{cm}^{2}\right)$ & 0.93 & 1.98 \\
$C_{1}\left(\mathrm{~F} \mathrm{~cm}^{-2}\right)$ & $2.43 \times 10^{-6}$ & $8.15 \times 10^{-8}$ \\
$\alpha$ & 1 & 1 \\
$R_{2}\left(\Omega \mathrm{cm}^{2}\right)$ & 26.03 & 19.19 \\
$C_{2}\left(\mathrm{~F} \mathrm{~cm}^{-2}\right)$ & $3.32 \times 10^{-4}$ & $6.79 \times 10^{-4}$ \\
$\alpha$ & 0.920 & 0.919 \\
$R_{3}\left(\Omega \mathrm{cm}^{2}\right)$ & 9.39 & 9.61 \\
$C_{3}\left(\mathrm{~F} \mathrm{~cm}^{-2}\right)$ & $7.24 \times 10^{-3}$ & $5.92 \times 10^{-3}$ \\
$\alpha$ & 0.364 & 0.291 \\
\hline
\end{tabular}

As for $R_{2}$, the cell treated with solution B showed a smaller value than the cell with no treatment. It is speculated that the hole transport was promoted at the $\mathrm{CuI} /$ guanidium thiocyanate interface. We presume that the improvement of hole transport was caused by reduction of the recombination at the $\mathrm{FTO} / \mathrm{CuI}$ interface.

\section{Conclusion}

A $\mathrm{TiO}_{2}$ layer from titanium hydroxide precursor solution has been developed as the dense blocking layer at the FTO/porous$\mathrm{TiO}_{2}$ interface. The crack-free $\mathrm{TiO}_{2}$ blocking layer was formed from solution $\mathrm{B}$ which had small total weight loss during heating and less thermal contraction during pyrolyzing at lower temperature. The electrode treated with solution B was presumed to enhance $J_{\mathrm{sc}}$, leading to the improvement of the conversion efficiency from 2.92 to $3.60 \%$. One of the main factors improving the $J \mathrm{sc}$ of the SSDSSCs may be reduction of the charge recombination at the FTO and CuI interfaces. The electrochemical impedance measurements revealed that the dense blocking layer reduced charge recombination of SSDSSCs at the interface between FTO and $\mathrm{CuI}$.

\section{References}

1) B. O' Regan and M. Grätzel, Nature, 353, 737-740 (1991).

2) M. K. Nazeeruddin, A. Kay, I. Rodicio, R. Humohry-Baker, E. Müller, P. Liska, N. Vlachopoulos and M. Grätzel, J. Am. Chem. Soc., 115, 6382-6390 (1993).

3) A. Hagfeldt and M. Grätzel, Chem. Rev., 95, 49-68 (1995).

4) M. Matsumoto, Y. Wada, T. Kitamura, K. Shigaki, T. Inoue, M. Ikeda and S. Yanagida, Bull. Chem. Soc. Jpn., 74, 387-393 (2001).
5) T. Ueki and M. Watanabe, Macromolecules, 41, 3739-3749 (2008).

6) J. N. Freitas, A. F. Nogueira and M.-A. D. Paoli, J. Mater Chem., 19, 5279-5294 (2009).

7) U. Bach, D. Lupo, P. Comte, J. E. Moser, F. Weissörtel, J. Salbeck, H. Speitzer and M. Grätzel, Nature, 395, 583-585 (1998).

8) S. Spiekermann, G. Smestad, J. Kowalik, L. M. Tolbert and M. Grätzel, Synth. Met., 121, 1603-1604 (2001).

9) J. Krüger, R. Plass, L. Cevey, M. Piccirelli and M. Grätzel, Appl. Phys. Lett., 79, 2085-2087 (2001).

10) K. Murakoshi, R. Kogure, Y. Wada and S. Yanagida, Chem Lett., 26, 471-472 (1997).

11) N. Fukuri, N. Masaki, T. Kitamura, Y. Wada and S. Yanagida, J. Phys. Chem. B, 110, 25251-25258 (2006).

12) J. Xia, N. Masaki, M. Lira-Cantu, Y. Kim, K. Jiang and S. Yanagida, J. Phys. Chem. C, 130, 1258-1263 (2008).

13) K. Tennakone, G. R. R. A. Kumara, A. R. Kumarasinghe, K. G. U. Wijayantha and P. M. Sirimanne, Semicond. Sci. Technol., 10, 1689-1693 (1995).

14) B. O' Regan and D. T. Schwartz, J. Appl. Phys., 80, 47494754 (1996).

15) K. Tennakone, G. R. R. A. Kumara, I. R. M. Kottegoda, K. G. U. Wijayantha and V. P. S. Perera, J. Phys. D Appl. Phys., 31, 1492-1496 (1998).

16) B. O'Regan, D. T. Schwartz, S. M. Zakeeruddin and M. Grätzel, Adv. Mater. (Deerfield Beach Fla.), 12, 1263-1267 (2000).

17) G. R. R. A. Kumara, A. Konno, G. K. R. Senadeera, P. V. V. Jayaweera, D. B. R. A. DeSilva and K. Tennakone, Sol. Energy Mater. Sol. Cells., 69, 195-199 (2001).

18) K. Tennakone, V. P. S. Perera, I. R. M. Kottegota, L. A. A. De Silva, G. R. R. A. Kumara and A. Konno, J. Electron. Mater., 30, 992-996 (2001).

19) G. R. R. A. Kumara, A. Konno, K. Shiratychi, J. Tukahara and K. Tennakone, Chem. Mater., 14, 954-955 (2002).

20) G. R. R. A. Kumara, S. Kaneko, M. Okuya and K. Tennakone, Langmuir, 18, 10493-10495 (2002).

21) Q.-B. Meng, K. Takahashi, X.-T. Zhang, I. Sutanto, T. N. Rao, O. Sato, A. Fujishima, H. Watanabe, T. Nakamori and M. Uragami, Langmuir, 19, 3572-3574 (2003).

22) P. M. Sirimanne, T. Jeranko, P. Bogdanoff, S. Fiechter and H. Tributsch, Semicond. Sci. Technol., 18, 708-712 (2003).

23) V. P. S. Perera and K. Tennakone, Sol. Energy Mater. Sol. Cells, 79, 249-255 (2003).

24) X.-T. Zhang, H.-W. Liu, T. Taguchi, Q.-B. Meng, O. Sato and A. Fujishima, Sol. Energy Mater. Sol. Cells., 81, 197-203 (2004).

25) J. Bandara and H. Weerasinghe, Sol. Energy Mater. Sol. Cells., 85, 385-395 (2005).

26) A. Fujishima and X.-T. Zhang, Proc. Jpn. Acad., 81, 33-42 (2005).

27) U. Opara Krasovec, M. Berginc, M. Hocevar and M. Topic, Sol. Energy Mater. Sol. Cells., 93, 379-381 (2009).

28) H. Yua, S. Zhanga, H. Zhaoa, G. Willb and P. Liua, Electrochim. Acta, 54, 1319-1324 (2009).

29) H. Sakamoto, S. Igarashi, K. Niume and M. Nagai, Org. Electron., 12, 1247-1252 (2011)

30) H. Sakamoto, S. Igarashi, K. Niume and M. Nagai, Org. Electron., 13, 514-518 (2012). 